\title{
A IDEOLOGIA NACIONALISTA REPUBLICANA NA HISTÓRIA DA LITERATURA BRASILEIRA, DE SÍLVIO ROMERO
}

Eduardo da Silva de Freitas

(UERJ)

\section{RESUMO}

Este artigo analisa a História da Literatura Brasileira, de Sílvio Romero, considerada como produto da ideologia republicana desposada pelo autor. Neste sentido, caracteriza em linhas gerais algumas disposições e intenções do movimento republicano que teve lugar no Brasil entre 1870 e 1889. A seguir, mostra-se como o nacionalismo derivado desta ideologia é atualizado naquela obra do historiador sergipano, impactando na construção da narrativa. PALAVRAS-CHAVE: Nacionalismo. Literatura. Historiografia.

\section{Introdução}

A respeito da História da Literatura Brasileira, de Sílvio Romero, pode-se dizer que ela é uma obra típica da historiografia literária oitocentista por guardar três características elementares do gênero. Em primeiro lugar, a história propõe uma síntese da produção literária brasileira desde os momentos iniciais da colonização portuguesa até os dias em que ela própria foi redigida. Além disso, seguindo a máxima de que "a história literária segue, como sempre, a política” (ROMERO, 2001, p. 61), ela representa a literatura como um apêndice da história política. Por fim, o privilégio concedido à história política implica certo comprometimento ideológico da compreensão dos fatos arrolados na narrativa.

Quanto a este último elemento característico, trata-se efetivamente da impregnação nacionalista comum às histórias da literatura nacionais, que, no caso da obra de Sílvio Romero, assume forma concreta na teo- 
ria da miscigenação, que se desenvolveu a partir da segunda metade do século XIX. Segundo ela, o país seria o resultado de uma mistura em que as disposições raciais dos grupos humanos que existiram desde os momentos iniciais da colonização desempenharam o papel principal no processo de construção do país.

Acrescente-se que a teoria da miscigenação presente na História da Literatura Brasileira, de Sílvio Romero tem seu significado preenchido a partir de certas ideias políticas que tiveram lugar em fins do século XIX, sobretudo entre os anos de 1870 e 1889 . São elas, em verdade, que estão na base da elaboração de todo o texto, servindo para construir certa representação da história literária condizente com os pressupostos políticos que defende. Oriundas do pensamento republicano que ganhou espaço no período mencionado, são essas ideias políticas que emprestam, em boa medida, sentido à obra do historiado sergipano, uma vez que permitem entender tanto os juízos que ele emite quanto as explicações que formula. Todavia, antes de verificar como as ideias republicanas impactam na construção da narrativa, é necessário esclarecer em que consistem.

\section{Aspectos gerais do pensamento republicano entre}

\section{0 e 1889}

O estabelecimento dos anos de 1870 e 1889 para a caracterização do pensamento republicano adotado por Sílvio Romero leva em consideração dois acontecimentos que podem ser tomados como marcos da difusão da ideologia republicana da geração do historiador sergipano. $\mathrm{O}$ primeiro ano prende-se ao momento inicial de expansão mais acentuada do pensamento republicano, que ganha fôlego no final da década anterior, exteriorizando-se no Manifesto Republicano. Documento publicado em 1870 , ele foi assinado assinado por diversos intelectuais e profissionais liberais. A última data é o ano da culminância daquelas ideias: é quando se altera a forma de governo da monarquia para a república, fato que empolgou amplamente os intelectuais republicanos.

Para a compreensão do quadro de ideias que tiveram ampla repercussão neste período e que foram desposadas por boa parte da inteligência brasileira contemporânea, o próprio Manifesto oferece uma entrada. Mais interessado em atacar a monarquia vigente do que apresentar um programa de ação, o documento identifica a forma do governo como responsável 
pelos males do país. O teor da crítica volta-se para a falta de liberdade, provocada pela concentração do poder na figura do imperador. Os republicanos reclamavam de que no país "só h[avia] um poder ativo, onímodo, onipotente, perpétuo, superior à lei e à opinião" sendo ele "o poder sagrado inviolável e irresponsável" (MANIFESTO, 1979, p. 63). Da perspectiva deste grupo, tal situação geraria diversos privilégios de religião, de raça, de conhecimento, de posição, dando espaço assim a "todas as distinções arbitrárias e odiosas que criam no seio da sociedade civil e política a monstruosa superioridade de um sobre todos ou de alguns sobre muitos" (MANIFESTO, 1967, p. 63).

Em correlação com essa crítica direta, o documento registra uma interpretação para a forma de governo então vigente. Segundo ele, a manutenção da forma monárquica significaria a manutenção do estatuto colonial, dadas as circunstâncias que envolveram o processo de independência do país, em que seu mandatário foi tomado da família real portuguesa. De acordo com o documento, a instauração da monarquia no Brasil manteve "a realidade do sistema que se procurava abolir" (idem, p. 64), frustrando o movimento de independência, porque o Império teria sido instaurado por meio da usurpação e da traição da vontade do povo.

Considerando esta disposição geral do documento, resta dizer que nele se encontram um reparo à forma interna da organização do poder e outro à situação sociopolítica do país em relação aos demais Estados sul-americanos. No primeiro caso, os republicanos colocavam em dúvida a própria legitimidade da forma de governo então vigente, pois entendiam ser inconcebível a existência de uma monarquia aliada à soberania nacional, uma vez que os princípios de sustentação de cada regime pressupõem formas diferentes de legitimação. Enquanto um se pauta pela hereditariedade e pela graça divina, o outro se baseia na vontade livre e soberana dos cidadãos. A "monarquia temperada" (MANIFESTO, 1979, p. 79), pretendendo a um tempo ser hereditária e representativa, seria absurda e repugnante. De outra parte, o documento registra certo incômodo diante do fato de o Brasil ser a única monarquia numa América organizada por repúblicas. Assim, os republicanos consideravam "a monarquia uma anomalia na América, onde só existem repúblicas” (COSTA, 1985, p. 268), porque entendiam ser a forma de governo brasileira "em sua essência e em sua prática, antinômica e hostil ao direito e aos interesses dos estados americanos" (MANIFESTO, 1979, p. 82).

Pelo que se pode perceber do Manifesto, a crítica à forma de governo por seu caráter centralizador, continuísta e anômalo coadunava-se ao apelo 
à descentralização do poder, à ruptura com a herança colonial e à adequação das ideias e das práticas aos interesses coletivos. A compreensão da realidade nestes termos implicou uma reinterpretação da nacionalidade do país. Até a década de 1870, a ideia de que a nacionalidade brasileira era especialmente tributária de Portugal e do governo português foi predominante em certas áreas. Apesar de a literatura da época voltar-se para os costumes indígenas, isso jamais significou o questionamento da primazia do português no estabelecimento da civilização no Brasil. Para a inteligência romântica, o índio era apenas "uma imagem do passado e, portanto, não apresentava qualquer ameaça à ordem vigente" (LEITE, 1983, p. 183). Com efeito, era mais presente entre a inteligência da época, a posição representada na História Geral do Brasil, de Francisco Adolfo Varnhagen, obra síntese do pensamento monarquista. Nela, se justifica "a dominação colonial, a submissão do povo, os direitos das elites" (REIS, 2000, p. 33), fazendo-se a apologia do português e da colonização empreendida na América, como se pode ler abaixo:

Claro está que, se o elemento europeu é o que essencialmente constitui a nacionalidade atual, e com mais razão [...] constituirá a futura, é com esse elemento cristão e civilizador que principalmente devem andar abraçadas as antigas glórias da pátria, e por conseguinte a história nacional. (VARNHAGEN, 1853, p. XXV)

Assim, quando os intelectuais republicanos formulam sua posição contra a monarquia, o que tentam é destituir a maneira de encarar o país que a monarquia trazia consigo. Entende-se, assim, que a crítica se voltasse contra tudo que pudesse ser identificado como herança indesejada do processo de instauração do governo autônomo no Brasil. Aliás, não só as instituições monárquicas foram alvo das investidas dos republicanos, mas também certas formas de pensar que se entendiam derivadas dela, bem como as instituições que lhe davam apoio. Nesse sentido, são atacadas as ideias filosóficas que tiveram ampla repercussão no Brasil até 1870 e que, inspiradas no pensamento de Victor Cousin e imbuídas de pressupostos metafísicos, produziam uma doutrina que condizia "com os ideais monárquico-constitucionais da jovem aristocracia sul-americana" (COSTA, 1967, p. 75), e se prestava a respaldar o regime. Dentre as instituições, interessa destacar sobretudo os ataques à Igreja, vista pelos republicanos como "como uma instituição que representava o passado, reacionária, contrária ao progresso e, o que era pior, aliada natural da Monarquia" (OLIVEIRA, 1990, p. 161).

Identificando os males do país com a monarquia, seus símbolos e 
aliados, os republicanos pretenderam romper com esta herança. E a realização desse projeto implicava a fundação da nacionalidade em outras bases. O questionamento da monarquia em favor da república, realizado politicamente como repúdio à centralização e à forma de governo, correspondeu à valorização de outros componentes simbólicos que são utilizados para redirecionar a forma da nacionalidade brasileira. Assim, se a monarquia, a rigor, implicou a apologia do processo colonizador e a valorização do elemento português na construção da nacionalidade brasileira, os republicanos colocavam o meio brasileiro como seu elemento constituinte e o "povo" como figura que pretendia abranger também os índios e os negros. Embora fosse ingênuo pensar que na ideia "povo" lançada pelos republicanos haveria algum pressuposto de igualdade entre as etnias, é preciso reconhecer que o português já não figurava mais sozinho, senão que em interação com os habitantes primitivos e os negros. Com efeito, houve mesmo algum espaço para a inclusão desses contingentes para a composição da nacionalidade brasileira. Para boa parte da inteligência republicana, ser «brasileiro significa[va] viver em um país geograficamente diferente da Europa, povoado por uma raça distinta da europeia» (ORTIZ, 1986, p. 17).

Relacionada a essa mudança conceitual básica da nacionalidade, pode-se mencionar a valorização das regiões interiores do país. Sendo a centralização identificada com a Corte e com o Rio de Janeiro, a proposta de descentralização traduz-se igualmente no realce da vida nos sertões. Além disso, deve-se mencionar que, em lugar da filosofia idealista, os republicanos, de maneira geral, adotaram um pensamento materialista e científico. A inteligência de então procurava entender os mais diversos fenômenos que tinham lugar na sociedade brasileira partindo de um modelo de explicação fornecido pelas ciências biológicas. Ao pensamento científico também se recorreu para atacar a Igreja Católica, acusada de promover o obscurantismo, por meio da veiculação de uma cultura retórica, empolada e vazia, retardando o desenvolvimento do país.

Esse é mais ou menos o panorama da situação vivida pela inteligência brasileira de fins do século XIX; são essas as posições que, em geral, atacam e defendem. Certamente, uma análise mais detida dos escritos daqueles que viveram este período apontaria diferenças importantes entre um e outro intelectuais. Caso se repare na dispersão que houve na inteligência republicana logo após a proclamação da República, será possível perceber que o acordo não era tão geral assim. No entanto, até o ano de 
1889 as divergências permaneceram latentes, e os esforços se concentraram efetivamente no ataque ao regime estabelecido e na promoção do ideário republicano.

\section{A História da Literatura Brasileira, de Sílvio Romero}

É neste quadro que se insere a História da Literatura Brasileira, de Sílvio Romero. Ela é uma das formas de expressão desse conjunto de ideias que teve lugar entre os anos 1870 e 1889. O travo ideológico previsto pelo gênero textual das histórias literárias atualiza-se no caso de Sílvio Romero pela adoção do ideário republicano, que ganha forma na sua teoria da miscigenação. Com ela, o autor pretende substituir a forma do nacionalismo monarquista, colocando em seu lugar a coletividade das etnias que existiram no Brasil a partir de sua ocupação pela coroa portuguesa. É nesse sentido que vão suas palavras ao declarar que:

A história do Brasil, como deve ser hoje compreendida, não é, conforme se julgava antigamente e era repetido pelos entusiastas lusos, a história exclusiva dos portugueses na América. Não é também como quis de passagem supor o romanticismo, a história dos tupis, ou, segundo o sonho do africanismo entre nós, a dos negros do Novo Mundo.

É antes a história da formação de um tipo novo pela ação de cinco fatores, formação sextiária em que predomina a mestiçagem. (ROMERO, 2001, I, p. 57)

O que está em jogo para o historiador sergipano é mostrar, por meio da literatura, entendida como todas as manifestações escritas da sociedade, como o "povo" brasileiro foi-se constituindo pela mistura das raças. Essa proposta está na base de sua obra e interfere tanto na apreciação que faz dos textos e autores que aborda, quanto na maneira de organizar a narrativa. Com efeito, sendo teoria da miscigenação a forma pela qual se atualiza o ideário republicano e se ela ocupa a posição central na história literária de Sílvio Romero, não é de estranhar que impacte sobre todos os aspectos do texto, seja na parte propriamente narrativa, seja na parte em que se analisam as obras.

Concebendo assim a História da Literatura Brasileira, este trabalho detém-se, no desenrolar da narrativa para que se veja como suas ideias sobre a nacionalidade se efetuam. Deixando de parte o "Livro I", em que o autor apresenta suas teorias, comece-se com o "Livro II", já que é neste 
ponto que se dá início à narrativa. Ali, aborda-se o século XVI, quando se dá início à colonização do Brasil pelos portugueses.

Partindo da chegada dos colonizadores, Sílvio Romero entende que o esforço civilizador cabe ao português, a quem os indígenas e africanos teriam ajudado. Embora considere estes dois grupos inferiores, isso não significa que o prestígio recaia sobre o elemento europeu. Ao invés disso, o foco é projetado sobre como estes grupos interagiram para dar origem ao "povo brasileiro". Assim, anota:

O português era sem dúvida o mais forte; mas, posto em contato com tupis e africanos, debaixo de um clima, num meio diverso do seu, ele diluiu-se, por assim dizer, tomou novas feições, transformou-se, concretizando-se num produto novo, o povo brasileiro, que, se se diversifica do negro e do índio, também é bem diverso dele europeu. (ROMERO, 2001, I, p. 156)

Concentrando-se na sua teoria sobre a miscigenação, Romero entende que o século XVI teria desempenhado um papel importante, pois julgava que "o progresso ulterior do Brasil tem consistido nos últimos três séculos em prosseguir no plano traçado a largas linhas naquele tempo" (idem, p. 156). Mesmo que afirme naquela época não teria havido "uma literatura no sentido especial que se dá a este termo" (idem, p. 15), o período representa o momento embrionário da formação do "povo brasileiro". Neste sentido, ressalta que nos núcleos de população em Pernambuco, na Bahia e no Rio de Janeiro, surgia uma população mestiça diversa de seus progenitores.

Sabendo que é procedimento típico das histórias da literatura nacionais interessar-se mais pelo viés "nacional" do que pelo "literário" da história, note-se que Sílvio Romero procura estabelecer o "povo brasileiro" como figura central de sua narrativa. O último período da citação acima deixa claro isso e a continuidade do texto o confirma. Porém, isso fica mais evidente quando se notam os comentários feitos a respeito de José de Anchieta, personagem central do capítulo.

Sem que se entre nos comentários feitos por Romero a respeito das obras do frei, observem-se algumas apreciações dele relativas ao próprio religioso. Depois de afirmar que o padre seria o tipo modelar de inaciano e de tecer alguns comentários sobre sua produção escrita, o historiador aponta a importância do jesuíta para a literatura brasileira, ressaltando ter sido Anchieta quem escreveu as primeiras peças teatrais representadas na América e as primeiras poesias. Mas chama atenção justamente o foco 
que Romero lança sobre o relacionamento do padre com o índio e os negros:

E o moço padre era o mais próprio para levar ao cabo a tarefa que lhe coube na história. Filho de uma descendente dessas raças cruzadas das Canárias, aquele insular, não tendo o orgulho nativo do português ou do espanhol de sangue puro, era naturalmente levado a simpatizar com as gentes selvagens, com os pobres fetichistas negros e índio, em que a vaidade europeia não podia habituar-se a ver entes humanos. (ROMERO, 2001, I, p. 168-169)

Pela leitura do capítulo como um todo, pode-se inferir que para Sílvio a tarefa que coube a Anchieta foi justamente ser o primeiro a exprimir o que haveria de ser a essência da nacionalidade brasileira. Mesmo sem ter nascido no Brasil, Anchieta, filho de um espanhol com uma canarina, estaria apto a ser este instrumento de vazão da nacionalidade brasileira, à diferença de escritores como Gândavo, Gabriel Soares e outros, que "passaram pelo país e não se abrasileiraram" (idem, p. 160).

Antes que se prossiga, façam-se duas observações sobre a construção da narrativa no que diz respeito a outros desdobramentos da adoção de uma perspectiva republicana para a formulação da nacionalidade brasileira de então. Em primeiro lugar, note-se a incorporação do pensamento científico, segundo a forma típica da época, por Sílvio Romero neste trecho. Assim, a explicação que dá para o fato de Anchieta ocupar um lugar de destaque na história da literatura brasileira, baseia-se na circunstância de que o padre era um mestiço.

Em segundo lugar, não se deve deixar de notar que o elogio de Anchieta não reflete qualquer apologia da Igreja. Isso, porque, além de a Igreja Católica estar profundamente ligada à monarquia desde o período colonial, havia no pensamento republicano a ideia de que promovia o obscurantismo. De modo geral, Romero avalia que o papel da influência jesuítica não teria sido "de todo feliz na formação intelectual e estética da nova sociedade", pois teria sido "seu humanismo pesado e abstrato, suas fórmulas casuísticas e vãs, a pobreza de sua intuição artística” (idem, p. 170), a base da educação estética da colônia.

A sequência da narrativa trata do século XVII. Caracterizado como "fase de perigo" (idem, p. 175), devido aos ataques estrangeiros à então colônia portuguesa na América, é também o momento em que desponta o «sentimento nacional» (idem, p. 175). No combate às forças estrangeiras, viria a se consolidar o movimento de união entre o português, o negro e o 
índio. Para Romero, neste momento "o entrelaçamento [entre os grupos] é perfeito, o brasileiro é já uma realidade" (idem, p. 175).

Romero entende que, naquele século, teria havido um confronto em que se teriam colocado frente a frente as tendências à preservação do viés português e a inclinação para consolidação do "povo brasileiro". O período seria marcado pela disputa de "duas forças antagônicas, que sem se combaterem diretamente uma a outra, trabalhando em esferas opostas, podem ser consideradas como diametralmente inimigas, ainda que se julgassem aliadas e amigas" (idem, p. 175).

Romero identifica nas figuras de Gregório de Matos e Antônio Vieira a síntese dessa luta. Enquanto, para ele, o padre "simboliza o gênio português, com toda a sua arrogância na ação e vacuidade nas ideias", o poeta "é a mais perfeita encarnação do espírito brasileiro, com sua facécia fácil e pronta, seu desprendimento de fórmulas, seu desapego aos grandes" (idem, p. 176). Portanto, de um lado estaria o jesuíta, mais uma vez, definido como pedante e vazio; do outro, estaria a figura rebelde do poeta, desconfiado dos integrantes do clero e do governo.

$\mathrm{O}$ viés republicano da interpretação dos fenômenos que aborda é evidente tanto na afirmação da existência do "brasileiro", quanto na caracterização dele como mistura do português, do negro e do índio. Esse entendimento, de uma parte, sugere que o brasileiro seria uma figura há bastante tempo diferenciada no cenário da civilização ocidental e refuta, de outra parte, a interpretação da história que reconhecia em Portugal o único fator positivo na constituição da sociedade brasileira.

Aliás, mais adiante, Sílvio Romero se posiciona com veemência contra tal entendimento da história do Brasil. Para ele, se esta fosse a história da persistência do elemento português, além de se incluir no rol das figuras que fundaram a literatura brasileira todos os colonos, governadores e reis da metrópole, cujas ações estavam voltadas para a opressão da colônia, deveriam ser incluídos também entre "os mais notáveis fundadores da literatura pátria, o carrasco que precipitou da forca a Tiradentes e o soldado que atirou certeiro ao coração do Padre Roma..." (idem, p. 182).

Não sendo preciso insistir na característica mistura de política e literatura neste tipo de obra, registre-se que as duas personagens mencionadas ao final da citação remetem a figuras consideradas revolucionárias. Joaquim José da Silva Xavier, o Tiradentes, foi tomado como símbolo da rebeldia pelos pensadores republicanos. Igualmente o foi José Inácio Ribeiro de Abreu e Lima, o Padre Roma, que deixou a vida eclesiástica 
e foi o pai de José Inácio Abreu e Lima, o bolivariano General Abreu e Lima. O Padre Roma participou da revolução pernambucana de 1817, tendo sido preso e executado pelo governo monárquico. Nesta condição, representam eles oposição à ordem estabelecida, ao poder metropolitano, sendo aproveitados pela ideologia nacionalista republicana. Além disso, não deve passar despercebido que a invocação dessas personagens revolucionários se dá no mesmo capítulo em que sobressai Gregório de Matos, definido como "um batalhador social" (idem, p. 193).

Diante disso, não é de estranhar que o poeta baiano seja a personagem principal do capítulo. É para ele que Sílvio Romero volta todo seu entusiasmo, reconhecendo nele os atributos mais expressivos da nacionalidade brasileira. Neste sentido, Gregório de Matos é alçado à posição de verdadeiro fundador pela literatura brasileira. Apesar de vir depois de Anchieta, o poeta baiano recebe esta honraria porque, no entender de Sílvio Romero, teria sido ele quem primeiro teria representado integralmente a mistura de raças no Brasil, ao passo que o padre se deteve nos indígenas e nos portugueses. Ao que parece, antecipando um possível reparo às suas ideias, ressalta, ainda, que apesar de Gregório de Matos ser filho direto de portugueses, a mestiçagem do poeta deu-se no sentido moral. Toda a caracterização de Gregório tende a apontá-lo como uma figura do povo, um representante típico.

Fazendo uma leitura biográfica da produção poética atribuída a Gregório, ressalta ter sido "pelo lado humorístico e satírico que o baiano foi um fator nacional", porque com isso deu "entrada a certos termos puramente brasileiros" empregando "um torneio de linguagem inteiramente popular" (idem, p. 190). Diante disso, não poderia ser outra a conclusão do historiador sergipano: "Gregório de Matos é o genuíno iniciador de nossa poesia lírica e de nossa intuição étnica. O seu brasileiro não era o caboclo, nem o negro, nem o português; era já o filho do país, capaz de ridicularizar as pretensões separatistas das três raças." (idem, p. 193). Em suma, a posição de Gregório de Matos na história literária de Sílvio Romero está intimamente relacionada ao fato de ver no poeta uma espécie de precursor da rebeldia ao governo metropolitano e de notar na obra atribuída ao escritor baiano uma manifestação do espírito nacionalista segundo a configuração que lhe deu o historiador sergipano.

Tendo visto como se configura a narrativa quando trata do século XVII e a maneira pela qual implica a valorização de Gregório de Matos, passe-se agora para o século seguinte, observando especificamente o 
que registra sobre os eventos que ocorreram a partir da segunda metade. No seu entender, o século XVIII foi marcante tanto na Europa quanto na América. No caso desta, foi a época em que se preparou a liberdade das colônias. Para o Brasil, segundo Romero, esta seria «uma época histórica importantíssima», embora os «cinquenta primeiros anos sejam de um valor mais exíguo» (ROMERO, 2001, I, p. 194). De qualquer modo, quanto à primeira metade do século não deixa de reconhecer nela um adensamento da vida social que se expressa na criação das academias, no desenvolvimento do teatro, no aumento do número de escritores, poetas sobretudo. Do modo como está caracterizada, a primeira metade dos setecentos apenas dá continuidade ao que se vinha constituindo desde o início da colonização do Brasil.

Mas é na segunda metade daquele século que Sílvio Romero identifica a época mais importante da história do país. Segundo ele, é este «o momento decisivo de nossa história: é o ponto culminante; é a fase da preparação do pensamento autonômico e da emancipação política» (idem, p. 215). Tal caracterização deste período liga-se ao fato de entender que o destino do Brasil como corpo político autônomo começou efetivamente com as gerações que viveram entre 1750 a 1830 . Assim, depois de uma digressão em que reitera suas concepções sobre o nacionalismo e filosofia da história do Brasil, afirma ser justamente aquele o momento em que a nacionalidade brasileira está consolidada: «Aí já não aparecem isolados a natureza e o caboclo. Aparecem a história com todas as suas lutas, o passado com todos os seus feitos; índios, brancos, negros, solo, natureza, lenda, aspirações, a vida, o povo em suma...» (idem, p. 219).

O entusiasmo notório de Sílvio Romero com este período tem a ver certamente com sua interpretação republicana da história do Brasil. Por um lado, vê no papel desempenhado pela coroa portuguesa na colonização do Brasil um estorvo à melhoria das condições materiais da colônia, na medida em que ela se constituía como opressora; por outro, ele reveste de certo caráter heroico os que teriam conseguido fazer a colônia progredir. Nesse sentido, aponta a omissão da coroa, afirmando que «o desenvolvimento da colônia foi quase em tudo um fato conquistado a esforços nossos contra a vontade expressa do governo português» (idem, p. 220), e também enfatiza o martírio dos brasileiros, ao dizer que «nosso progresso foi, pois, conquistado quase sempre a esforços nossos, amassado com as nossas lágrimas e com o nosso sangue» (idem, p. 220).

É de se notar nas palavras de Sílvio Romero a recorrência do 
pronome "nosso". Efetivamente, neste ponto, ele indica não só a simpatia do historiador por aqueles que teriam contribuído para a emancipação, como também sugere movimento interpretativo da história. Por trás daquele pronome, reside a crença de que os homens do passado contribuíram para criar um Brasil à feição das ideias republicanas, defendidas pelos contemporâneos do autor. Com este movimento, ele estabelece uma tradição ideológica que teria sido incorporada pela geração de 1870 .

No que se refere às gerações que viveram entre meados dos setecentos e inícios dos oitocentos, elas seriam, no fundo, um só corpo. Embora mudassem certos detalhes, de uma época à outra, todos lutavam pela autonomia do Brasil. Assim, a diferença existente consistia somente no fato de que uns teriam lutado contra a coroa portuguesa, ao passo que os outros contra a monarquia brasileira, considerada herdeira desta última.

Depois disso, a narrativa é mais ou menos suspensa e todo o restante do tomo primeiro é dedicado às anotações biográfica e às análises das obras, entrecortadas frequentemente por digressões. Apenas no tomo segundo é que seu fio é recuperado, continuando a partir dos anos de 1830 para tratar do Romantismo. Sem que se detenha na diferença organizacional dos dois tomos da obra, que em seu segundo tomo aborda especialmente a poesia em detrimento do romance e do teatro, mencionados apenas muito brevemente em certos momentos, sintetize-se a percepção do historiador sobre o Romantismo e sua repercussão no Brasil.

Para Romero, o grande feito do Romantismo foi ter liberado a literatura de esquemas pré-definidos. Assim, se a «poesia clássica tinhas ideias, linguagem, forma predeterminadas; a poesia nova quebrou o molde antigo e vazou-se em tantos moldes novos, quantos povos e até quantos indivíduos de gênio poetaram» (ROMERO, 2001, II, p. 607). No caso do Brasil, reproduzindo uma apreciação já então consagrada do movimento, aponta que seu maior mérito teria sido «arrancar-nos em parte da imitação portuguesa, aproximar-nos de nós mesmos e do grande mundo» (idem, p. 612).

Apesar disso, o balanço que faz do movimento como um todo não deixa de apontar certos limites à maneira pela qual empreendeu esta aproximação. Ela teria sido frustrada pela manutenção de certas tendências típicas do classicismo, como foi o caso e Magalhães e dos que gravitaram em torno dele. De outra parte, censura a maneira pela qual o movimento frequentemente insistiu em alçar o indígena à símbolo maior da nacionalidade e da literatura brasileiras. Nesse sentido, apesar de entender 
que o indianismo teria sido a expressão mais bem acabada do movimento romântico brasileiro, tendo-se tornado bastante popular, seu problema consistiria em atribuir ao nativo americano um papel muito maior do que julgava adequado. Para o historiador, que pensava a nacionalidade brasileira a partir da teoria da miscigenação, segundo uma interpretação em que o português ocupava o topo da hierarquia em relação a índios e negros, a exaltação do índio feita pelo Romantismo no fundo assentava-se num erro, inclusive porque não atinaria ao fato histórico de terem sido os habitantes primitivos derrotados pelos portugueses.

Contra isso, anota a certa altura de seu comentário sobre Gonçalves Dias, que são «o gênio, a força primeira do brasileiro e não os do gentio que devem constituir a poesia, a literatura nacional" (idem, p. 746), destacando as palavras chave do problema. Mais adiante, anunciando a maneira pela qual a concebe o papel da poesia indianista, declara que foi "uma poesia útil como um tônico, um abalo necessário imposto aos nervos de nossos burgueses para os arredar da mania das imitações europeias; mas não podia ser exclusivista" (idem, p. 749).

Não seria preciso dizer que esta restrição ao Romantismo é derivada da maneira como atualiza as ideias sobre a nacionalidade brasileira a partir dos ideais republicanos. Formulando-a nos termos da teoria da miscigenação, insistindo em que a nacionalidade deveria assentar-se na mistura de três raças, que gerariam um ente novo o brasileiro, pode-se dizer que é um índice de coerência a rejeição do indianismo promovido por alguns românticos. Em verdade, assim como faz questão de refutar a opinião dos que colocam os portugueses como os únicos elementos positivos na formação do povo brasileiro, assim também não se satisfaz com a ideia que substitui os europeus pelos indígenas americanos.

Antes de se passar aos comentários finais da narrativa, é preciso apontar uma característica marcante do segundo tomo da obra. Trata-se justamente de haver uma redução das referências a fatos políticos para explicações dos fatos literários. Certamente, isso não significa que o fenômeno literário deixe de ser um apêndice da vida social, pois em várias passagens a posição ancilar da literatura é afirmada. Mas no segundo tomo da História da Literatura Brasileira, possivelmente por abordar a parte da história em que o Brasil já é um país, uma entidade autônoma politicamente, a derivação dos movimentos literários a partir de eventos políticos não é tão intensa. A questão de se provar a existência de uma nacionalidade que se lastreia pela literatura perde um pouco de sua energia. 
A propósito, note-se que, nos próprios trechos citados, ganham espaço as considerações sobre o Romantismo pelo seu viés artístico. O procedimento mais comum a partir de então é abordar o nacionalismo a partir dos textos e dos autores, com diminuição da recorrência às explicações políticas.

Passando ao final da narrativa, repare-se que a proposta feita por Sílvio Romero colocava como limite para sua História a década de 1870. É este o momento em que se dá "a dissolução do romantismo na poesia brasileira" (ROMERO, 2001, I II, p. 1019), em favor da poesia condorei$r a$ ou hugoana, cuja origem se deu dentro do próprio movimento que viria destruir. Segundo Sílvio Romero, seriam três as épocas dessa nova tendência: entre 1863 e 1870, a primeira, "puramente poética e ainda exercida sob a influência do romantismo"; de 1870 a 1877/8, a segunda, quando "começaram as reações críticas em face do romantismo em geral; e a terceira, de 1878/9 até os dias da publicação da obra, em que "os estudos jurídicos e sociais toma a dianteira à poesia" (idem, p. 1020). Alegando que deixaria para um outro volume o acompanhamento das duas últimas, o historiador detém-se no primeiro momento.

Esta "sexta e última fase do romantismo", como o autor denominou este período, é definida como um momento de ruptura com os paradigmas daquele movimento. É a época em que surge a "escola literária do Recife" (idem, p. 1020). De acordo com Sílvio Romero, esta cidade teria sido o centro que superou todos os outros cantos do país pela "iniciativas das ideias" (idem, p. 1022). Estas ideias, todavia, teriam ficado quase ignoradas por causa do "desprezo da capital para com a imprensa provinciana" e devido à "posição pouco vantajosa" (idem, p. 1023) dos escritores.

Sob a liderança de Tobias Barreto, teriam os jovens poetas deixado as "velhas tendências", tomando por "musa o patriotismo, o entusiasmo estético e o amor", junto a uma poesia filosófica e lirismo sadios, cuja intenção consistia em "banir o byronismo afetado e o lamartinismo lamuriento" (idem, p. 1023). O logro que teria retirado da escola do Recife o mérito da inovação teria ocorrido devido à mudança de Castro Alves - segundo Sílvio Romero, um discípulo menor de Tobias Barreto - para o Rio de Janeiro e São Paulo, onde criou seus próprios discípulos que teriam arrogado para ele o título de fundadores da poesia hugoana.

A figura de Tobias Barreto simbolizaria certa tendência à descentralização defendida e utilizada pelo pensamento republicano em suas concepções sobre a nacionalidade brasileira. Na relação que Sílvio Romero estabelece entre Castro Alves e o escritor sergipano, o que se sugere 
é uma mudança de sentido no deslocamento das manifestações culturais do Brasil: em lugar de um movimento da capital para as províncias, teria havido um deslocamento no sentido inverso. Essa mudança do sentido das influências entre Corte e província seria uma expressão do grau de desenvolvimento que a nacionalidade teria então atingido. Neste caso, as realizações culturais não só não dependem diretamente proximidade com a Corte, como também são capazes de influenciá-la. A ênfase numa figura que se teria destacado fora da capital do Império seria uma maneira de demonstrar que sua geração encarnaria efetivamente o "povo brasileiro", autóctone, sem dependência do português.

No mais, considerando o momento em que escreveu, é preciso reconhecer que, por uma questão de lógica, a proposta de Sílvio Romero não poderia se estender além dos anos a que se dedica. Não haveria como escrever uma história dos anos que ainda estariam por vir. Embora o capítulo VI não seja propriamente o ponto final da obra, vale notar que os autores que integram o capítulo seguinte da história literária do historiador sergipano são apontados como discípulos do líder da escola de Recife. De fato, no capítulo VII, a narrativa já está concluída nada mais havendo senão uma análise dos poetas e suas obras.

Acrescente-se a isso o fato de que o capítulo é quase todo dedicado a Tobias Barreto, num tratamento muito mais alentado do que o dispensado a qualquer outro autor. Este fato, mais do que indicar a índole exagerada de Sílvio Romero, pode ser entendido como uma forma de efetuar o elogio de sua geração e do grupo de que fez parte. Parando a narrativa neste ponto e da maneira entusiasmada, Sílvio Romero sugere que sua geração não ocupa só o ponto limite da história, mas também o mais alto, construindo justamente uma espécie de final apoteótico para sua História da Literatura Brasileira. Nesse sentido, considerando sua observação de que este seria um momento de ruptura, pode-se entender nisso uma apologia também à sua concepção de nacionalidade nos termos do pensamento republicano. Seria este o momento em que se vê com clareza a nacionalidade brasileira completa e acabada, por assim dizer, conforme a ideologia republicana de sua geração.

\section{Conclusão}

A História da Literatura Brasileira, de Sílvio Romero, pode ser concebida a partir dos ideais republicanos que tiveram lugar no Brasil em fins do século XIX, sobretudo entre 1870 e 1889 . Isso fica eviden- 
te pela maneira como Ś́lvio Romero constrói sua narrativa, atualizando pensamentos veiculados por aquela geração de intelectuais republicanos. Com efeito, a interpretação e a explicação dos fenômenos que arrola em sua obra são orientados no sentido de, por um lado, desmerecer qualquer influência positiva da coroa portuguesa no processo de colonização do Brasil e, de outro lado, promover a figura coletiva "povo brasileiro". Nesse sentido, sua teoria da miscigenação é um conceito que se articula com as ideias republicanas, na medida em que promove a ideia de povo, em detrimento da concepção de que a nacionalidade brasileira seria uma espécie de "herança portuguesa".

Para Sílvio Romero, a história do Brasil seria a história do processo de integração entre os portugueses, indígenas americanos e os negros, de cuja miscigenação sairia o "brasileiro". A história literatura, por sua vez, sendo um reflexo da vida social, expressaria esta tendência geral. Desde os anos iniciais da colonização até o momento em que escreve sua obra, todos os fenômenos são pensados a partir dessa filosofia da história. 


\title{
THE REPUBLICAN NATIONALISM IDEOLOGY IN HISTÓRIA DA LITERATURA BRASILEIRA, BY SÍLVIO ROMERO
}

\author{
ABSTRACT \\ This paper analyses the Silvio Romero's Historia da Literatura \\ Brasileira, as a product from republican ideology undertaken by \\ the author. Accordingly, it characterizes generally some provisions \\ and intentions of the republican movement that took place in Brazil \\ between 1870 and 1889. Then, it shows how the nationalism de- \\ rived from that ideology and updated in that Silvio Romero's work \\ impacts on the building of the narrative. \\ KEYWORDS: Nationalism. Literature. Historiography.
}

\section{REFERÊNCIAS}

COSTA, Cruz. Contruibuição à História das Idéias do Brasil. Rio de Janeiro: Civilização Brasileira, 1967.

COSTA, Emília Viotti da. Da Monarquia à República: momentos decisivos. São Paulo: Brasiliense, 1985, $3^{\text {a }}$ ed.

LEITE, Dante Moreira. O Caráter Nacional Brasileiro. São Paulo: Pioneira, $1983,4^{\mathrm{a}}$ ed.

MANIFESTO Republicano. In: MELO, Américo Brasiliense de Almeida e. Os Programas dos Partidos e o Segundo Império. Rio de Janeiro: Casa de Rui Barbosa, 1979.

OLIVEIRA, Lúcia Lippi. A Questão Nacional na Primeira República. São Paulo: Brasiliense, 1990

ORTIZ, Renato. Cultura Brasileira e Identidade Nacional. São Paulo: Brasiliense, $1986,2^{\mathrm{a}}$ ed. 
REIS, José Carlos. As Identidades do Brasil: de Varnhagen a FHC. Editora da FGV, 2000.

ROMERO, Sílvio. História da Literatura Brasileira. Rio de Janeiro: Imago, 2001, $2 \mathrm{v}$.

VARNHAGEN, Francisco Adolfo de. História Geral do Brasil. Rio de Janeiro: Laemmert, 1853, 2v.

Recebido em: 15/12/2016

Aceito em: 06/06/2017 